Acta Poetica $26(1-2)$

PRIMAVERA-OTOÑO

2005

\title{
La literatura oral en la transición de la Edad Media al Renacimiento
}

\begin{abstract}
Alan Deyermond
Entre la Edad Media y el Renacimiento se destacan dos grandes cambios culturales. El primero es el paso de la cultura literaria de la oralidad a la cultura literaria basada en manuscritos y el segundo es el paso de los manuscritos literarios a la imprenta. Los cambios coexistieron. En este trabajo examino los cambios de la estilística y de los géneros literarios, demostrando cómo la mayoría de estos últimos fueron influidos por la oralidad.

Two main cultural changes coexisted between the Middle Ages and the Renaissance. One was the transition from orality to literacy; and the other, the passage from literary manuscripts into print. This paper deals with stylistic and genre transition, and demonstrates how almost all literary genres were influenced by orality.
\end{abstract}



Acta Poetica 26 (1-2)

PRIMAVERA-OTOÑO

2005

\begin{abstract}
Alan Deyermond ${ }^{1}$
Queen Mary and Westfield College, Universidad de Londres
\end{abstract}

\title{
La literatura oral en la transición de la Edad Media al Renacimiento
}

Toda época es de transición; no hay ningún momento estático en la historia de la humanidad. Las épocas que parecen más estáticas, casi sin historia, en la vida de una nación o de una persona, acaban por revelarse tarde o temprano como semilleros de algún cambio. Este mundo - como nos recuerda Jorge Manrique- es un camino, no "una morada sin pesar", aunque a veces morada parezca. Otras, experimentamos una conciencia aguda de transitoriedad, en nuestra vida o en nuestro tiempo: ése es el caso para la España del periodo que corre desde la segunda mitad del siglo Xv hasta principios de la centuria siguiente. Los hombres y las mujeres de la última etapa de la Edad Media no sabían que eran "medievales" — la palabra medieval es una invención polémica de escritores que, a su vez, se proclamaban "renacentistas"-; pero sí que eran conscientes de vivir en una sociedad y en una cultura precarias, fugitivas y hasta caducas. ${ }^{2}$

\footnotetext{
${ }^{1}$ La primera versión de este artículo fue publicada en la revista Edad de Oro 7 (1988).

2 Véanse los trabajos de Huizinga [1924] 1955 y Boase 1978, 181 y 194, n. 37.
} 
No voy a tratar en este trabajo los aspectos sociales y políticos de esta transición, sino los rasgos culturales y, particularmente, los aspectos orales de esa cultura. Porque, en efecto, dos de los cambios más profundos que afectan a la historia cultural se superponen durante ese largo periodo de cien años que va de la composición del Laberinto de la Fortuna a la publicación del Lazarillo de Tormes, con la Celestina de parteluz: el paso de la oralidad a la cultura literaria basada en manuscritos y el paso o camino de los manuscritos a la imprenta. Y no es que se superpongan solamente en un sentido teórico como la coincidencia cronológica de unos pueblos neolíticos en regiones aisladas con la cultura de los ordenadores en el mundo occidental, sino que coexisten dentro de un mismo país, de una misma ciudad, de una misma familia o hasta referidos a un mismo individuo. Sin embargo, esos cambios de tan gran calibre que a nosotros hoy nos parecen obvios por su mismo alcance, no se reflejaban como tales en la conciencia inmediata de quienes los estaban experimentando. Por ejemplo, la existencia de manuscritos copiados de libros impresos; la de impresores que trataban de imitar con sus tipos la letra manuscrita; los libros mitad manuscritos mitad impresos - pocos, pero los hay- (Goldschmidt 1943) etcétera; son hechos que revelan escasa conciencia del cambio fundamental que se estaba produciendo, de modo que no es difícil colegir que pocos eran quienes percibían que la imprenta iba a sustituir al manuscrito cuyo empleo y circulación floreció tanto antes como mucho después de la invención de Gutenberg (Trapp 1983).

Había, por supuesto, gente que sabía leer y escribir, que tenía el hábito de hacerlo antes de la introducción del libro impreso. La cuestión no es baladí, porque de tales hábitos de los lectores, dependía el triunfo del libro impreso; pero se trataba de una minoría. Es verdad que en la Inglaterra de principios del siglo XIV las relaciones sociales y jurídicas dejaron de depender de la memoria — como en la época anglo-sajona- 
para apoyarse en documentos; es verdad que en Castilla, en el segundo cuarto del siglo XV — nos lo cuenta el Arcipreste de Talavera - muchas mujeres podían amenizar un día aburrido con la lectura de Boccaccio. ${ }^{3}$ Sin embargo, sólo una minoría poseía la capacidad técnica de leer y escribir, y "capacidad técnica" no significa necesariamente la voluntad de utilizarla para la lectura erudita, de devoción o de recreo. Reyes y nobles, cuyas firmas llenan cartas y privilegios de la época, escuchaban a menudo un poema o un libro de aventuras de la boca de un juglar o de un recitador profesional. ${ }^{4}$ Es más, hay casos conocidos del empleo de técnicas orales por autores cultos, aunque no conozco ningún caso español equivalente a aquel tan llamativo de la enseñanza en un monasterio de la técnica de composición oral, tal y como parece haber ocurrido en la Inglaterra del siglo Ix (véase Renoir 1986). Pero no sería difícil buscar ejemplos de coexistencia de la cultura eclesiástica y la literatura oral durante esta época.

Me voy a referir, en consecuencia, a un tipo de transición diferente al cronológico, a la transición estilística y genérica. El concepto de un texto transicional, entre la composición oral y la escrita, chocaba hace años a los especialistas de la literatura oral. Albert B. Lord, a quien tanto debemos en este campo, dijo en The Singer of Tales, libro que inspiró, desde 1960, a los estudiosos de la literatura oral en el periodo medieval:

It is necessary for us to face squarely the problem of "transitional" texts. Is there in reality such a phenomenon as a text which is transitional between oral and written literary tradition...? It is worthy of emphasis that the question we have asked ourselves is whether there can be such a thing as a transitional text; not a period of transition between oral and written style, or between illiteracy and literacy, but a text,

\footnotetext{
3 Véanse Clanchy 1979 y Lawrance 1985.

${ }^{4}$ Véanse Chaytor 1945, cap. 6 y Frenk 1982.
} 
product of the creative brain of a single individual... who in composing an epic would think now in one way and now in another, or, perhaps, in a manner that is a combination of two techniques. I believe that the answer must be in the negative, because the two techniques are, I submit, contradictory and mutually exclusive. (Lord 1960, 128-129)

Esta negación tan rotunda fue matizada catorce años más tarde, cuando Lord tuvo que referirse al nuevo estado de las investigaciones:

I would like to suggest the possibility that in these poems, namely, the religious ones [en anglosajon], a new body of formulas to express the new ideas of the Christian poetry was beginning to be developed on the model of the oral traditional poetry. I am tempted to call the religious poetry "transitional" or perhaps "mixed". If that is the correct term, it applies not only to the formulas but to themes as well. (Lord 1974, 209) $)^{5}$

\section{Y más recientemente todavía:}

Memorization does occur at a later stage in the Serbo-Croatian tradition. That is to say, at a time when published, therefore fixed, texts were available and their prestige established, some traditional singers began to memorize the printed texts... When their memory failed them, they were still able to compose in the traditional way, and therefore, to continue to sing. Such a combination of processes results in "mixed" texts... (Lord 1981, 460)

\section{Y por fin:}

There seem to be texts that can be called either transitional or belonging to the first stage of written literature... When people

\footnotetext{
${ }^{5}$ Este número especial de la revista se reimprimió como Oral Literature: Seven Essays. Joseph J. Duggan (ed.), Edinburgh, Scottish Academic Press, 1975, donde el artículo de Lord ocupa las pp. 1-24 (23).
} 
began to write Anglo-Saxon verse... they continued to use the same traditional style, because there was as yet no other available... The way has been opened up to investigate the details of the creation and life of transitional texts. I have come to realize that, in fact, in such fields as Anglo-Saxon and other medieval poetries we have been doing just that all long. (Lord 1986, 479-80 y 494)

De acuerdo con esta reorientación teórica, los libros y ensayos sobre la tradición oral (véase Renoir 1986, 121-122) se ocupan cada vez con más frecuencia de textos transicionales, mucho más numerosos de lo que se creía.

Aunque la vida multisecular de los temas épicos fue estudiada magistralmente por Ramón Menéndez Pidal (1910) ya hace más de noventa años, la verdad es que no se suele considerar la épica tradicional española cuando se habla del ocaso de la Edad Media y los albores del Renacimiento. Las investigaciones de Samuel Armistead demuestran, sin embargo, que el poema épico que narra las hazañas juveniles del Cid, la Gesta de las mocedades de Rodrigo, del siglo XIII (perdido, pero que se conoce por las versiones de las crónicas) tuvo una descendencia bastante larga: no sólo la del poema de las $\mathrm{Mo}$ cedades de Rodrigo, obra de un clérigo palentino del siglo XIV, sino incluso versiones posteriores utilizadas por Lope García de Salazar en el Libro de las bienandanzas y fortunas (14711476), y por el cronista anónimo que refundió, entre 1504 y 1515, el Compendio historial de Diego Rodríguez de Almela (1978, 317-319 y 326-327). ${ }^{6}$ Son discutibles, desde luego, las fechas y el número de tales versiones. Para Armistead se trata de versiones orales, casi contemporáneas de los prosistas que las utilizaban, con otras versiones de la misma época o incluso posteriores a las que sirvieron de fuente a los romances. No estoy totalmente convencido. Me parece muy posible que Lope

${ }^{6}$ Véanse además sus estudios de 1963 y de 1973. 
García de Salazar y el cronista anónimo llegaran a conocer manuscritos, poéticos o prosificados, de poemas épicos del siglo XIV o principios del siglo Xv, y que algunas variaciones que para Armistead indican un poema distinto se debieran quizá a la recreación artística del prosificador. Las investigaciones de Mercedes Vaquero (1989) sobre la tradición del Cantar de Sancho II en las crónicas del siglo XV ofrecen nuevas razones para aceptar la hipótesis de una tradición de refundiciones épicas todavía viva en dicho siglo. De cualquier manera, no cabe duda de que la persistencia oral de varias tradiciones épicas se continuó hasta fecha bastante avanzada, y que influyó, directa o indirectamente, en la literatura de las últimas décadas del siglo XV y en las primeras del siglo XVI.

La épica, seguramente género oral en sus comienzos españoles (¿Los siete infantes de Lara, hacia el año 1000?), se transforma en género escrito, esto es: poemas épicos compuestos por escrito (como el Cantar de mío Cid, épica oral y escrita prosificada en la Estoria de España, de Alfonso el Sabio, y en otras crónicas), pero también continúa su transmisión oral - tal vez en versiones orales de los mismos poemas, seguramente a través del romancero- a lo largo del siglo Xv y el siglo XVI. De ahí el papel fundamental que jugó en la literatura del Siglo de Oro. Por ejemplo, Los siete infantes de Lara se retoman continuamente a partir de la Crónica de España (1543) de Florián de Ocampo - obra dentro de la tradición alfonsina, que gozó de gran prestigio hasta principios del siglo XVII- y a partir del romancero oral e impreso.

El romancero mismo demuestra la relación compleja entre lo oral y lo escrito. Es innegable que los romances se cantaron a lo largo de los siglos XVI y XVII — todavía hoy se cantan muchos, algunos después de quinientos años de vida-. Es seguro que muchos romances se compusieron oralmente, no sólo en el siglo XV, sino incluso en el siglo XVI. Es igualmente fehaciente que una sección impresionante de romances se incluyó 
en el Cancionero general de 1511, y que a partir de 1550 se imprimieron grandes colecciones, llamadas Cancionero o Silva de romances: estos tomos, tanto por su extensión como por su precio, estaban destinados prioritariamente a la lectura, y preferentemente a la lectura individual. Pero a su lado existieron multitud de pliegos sueltos — desde principios de siglo- que contenían un número muy reducido de romances y se conseguían por poco dinero. Aunque suponemos que la mayoría de estos pliegos sueltos se han perdido, no son pocos los que nos han quedado. ${ }^{7}$ Dos bibliófilos ingleses, Frederick J. Norton y Edward M. Wilson, siguiendo estas huellas, estudiaron precisamente la relación entre la tradición oral y los textos impresos de tales pliegos, concluyendo que los cantores de romances debían de utilizar textos impresos en su labor; que muchas variantes, otrora atribuidas a la tradición oral, se debían a la imprenta; que la tendencia a abreviar los textos de los romances deriva tanto — quizá más- de las necesidades del impresor que tenía que embutir el texto en cuatro hojas como del gusto del público. Bien es verdad, por otro lado, que algunas variantes de los textos de los pliegos podrían proceder de la tradición oral que conocía el impresor (Norton y Wilson $1969,55-60) .{ }^{8}$ En fin, una tesis doctoral norteamericana sobre el estilo de los romances juglarescos del ciclo carolingio, después de estudiar y documentar gran cantidad de fórmulas y rasgos del estilo oral, acaba por concluir — frente a la teoría de la escuela pidaliana- que aquellos romances se compusieron, en efecto, oralmente (Ochrymowycz 1975). Aun si dicha conclusión resulta equivocada — aunque hay que admitir que sus argumentos son convincentes-, los elementos orales apa-

7 Véanse Rodríguez-Moñino 1970 y 1973-74.

8 Además es interesante añadir que Albert B. Lord habló de la comprensión de textos orales por un coleccionador yugoeslavo de fines del siglo XIX en una ponencia del Coloquio Internacional "Oral and Written/Literate in Literature and Culture" (Novi Sad, septiembre de 1987). 
recen como tan fundamentales que no queda más remedio que pensar, al menos, en textos de carácter transicional.

No me referiré a los géneros marginales de la poesía popular oral: conjuros, oraciones y ensalmos, porque acaban de ser tratados en un largo artículo de José María Díez Borque (1985).

Por lo que se refiere al género de los debates, parece observarse una curiosa trayectoria que va primero de la oralidad a la escritura y, luego, vuelve a la oralidad. Los debates literarios medievales nacieron de una realidad social y recibieron su principal impulso de varios aspectos de la vida universitaria, eclesiástica y jurídica del siglo XII: las disputaciones escolásticas, la práctica de los pleitos jurídicos y los debates entre los representantes de iglesias o religiones (por ejemplo, el famoso debate de Barcelona, en 1263, entre el dominico converso Pablo Cristiano y el rabí Mosén Ben Nahman, bajo el patrocinio de Jaime el Conquistador).

Conocemos varios debates poéticos en el castellano medieval: Elena y María, Denuestos del agua y el vino, versiones del Alma y el cuerpo, así como dos debates en prosa. Durante el siglo XV el debate se configuró como recurso literario más que como género: Blas contra Fortuna, del Marqués de Santillana; Diálogo entre el Amor y un viejo, de Rodrigo Cota. Existen indicios de que el antiguo debate del alma y el cuerpo, derivado de una fuente latina, se popularizó, ya que existen varios pliegos sueltos de finales del siglo XV y del siglo XVI (Jones 1963). Este éxito sugiere, desde luego, su difusión oral. Además, el Diálogo de Rodrigo Cota fue refundido por un autor anónimo, en una versión - sin título, pero llamada ahora Diálogo entre el amor, el viejo y la hermosa- que parece estar destinada a la representación escénica.

Si volvemos la mirada hacia la poesía lírica, encontramos una terminología genérica que implica la oralidad, pero que no parece haber correspondido a la realidad literaria. En efecto, en los cancioneros manuscritos del siglo xv, desde el Can- 
cionero de Baena en adelante, un gran número de composiciones se rotulan como "dezir" o "canción". Los "dezires" son normalmente poemas largos — por ejemplo, el Dezir contra los aragoneses del Marqués de Santillana-, y nada indica que se hayan destinado a la recitación; su modo de difusión parece haber sido forzosamente la escritura y la lectura, no el decir y escuchar. ¿Es que en la prehistoria del género el nombre correspondía a otra realidad? No lo sabemos. En el Cancionero de Baena, que incluye la obra de la primera generación de poetas cortesanos de Castilla — 1360-90 - (Lang 1902), ${ }^{9}$ no se encuentra apoyo ninguno para aventurar qué concepto de "dezir" heredaron.

La "canción", por el contrario, parece haber llegado a los cancioneros como poesía cantada o, mejor todavía, cantable, ya que no se nos han conservado canciones con música anteriores a finales del siglo xv. Claro está que las canciones sí se prestaban a la lectura individual, pero la ausencia de la música en los manuscritos no indica sin más que no se cantasen. Recuérdese que los grandes cancioneiros gallego-portugueses, el de la Vaticana y el Colocci-Brancuti (o de la Biblioteca Nacional) carecen de música; pero el pequeño manuscrito de las cantigas de amigo de Martin Codax, del último tercio del siglo XIII, incluye la música de seis cantigas (Ferreira 1986). Al avanzar el siglo Xv, con todo, parece que con frecuencia el etiquetado "canción" ya no tenía valor musical alguno, sino referencia a un esquema métrico típico. ${ }^{10}$ Vale la pena recordar que la Cárcel de amor, de Nicolás Núñez, continuación de la obra del mismo título de Diego de San Pedro, incluye 25 poesías: 23 se denominan "letras", título que indica claramente su base en la escritura; pero existen también una canción y un villancico: no soy capaz de imaginar cómo habría sido posible

${ }^{9}$ El tomo II no se publicó.

10 Véanse los trabajos de Whinnom 1968-69 [1970] y Whetnall 1988. Y para la supervivencia de poesías cancioneriles en la lírica tradicional española e hispanoamericana véase Frenk 1982, 119-120. 
presentar oralmente la una o la otra, ya que están insertas en una obra en prosa destinada fundamentalmente a la lectura individual. Cárcel de amor, a pesar de sus poesías, no es una chantefable (Deyermond 1989). ${ }^{11}$

La transformación de la canción, paradójicamente, en un género no cantado, con las generaciones poéticas representadas en el Cancionero general de 1511, condujo a la formación de los grandes cancioneros musicales del periodo: Cancionero de la Catedral de Segovia, Cancionero musical de la Colombina, Cancionero musical de Palacio, Cancionero de Uphsala, etc. que recogen el ingente caudal de poesía lírica - villancicos, sobre todo- que se cantaban en la Corte de los Reyes Católicos, tema de Joaquín González Cuenca (1980), el excelente editor de las poesías castellanas del cancionero de la Catedral de Segovia.

Antes de volver mi atención hacia la prosa, no quisiera dejar de comentar otro aspecto relacionado con las consecuencias de la transmisión oral de largos poemas cultos o de parte de ellos. Un ejemplo que se cita a menudo es el de los fragmentos del Libro de Buen Amor incluidos en el supuesto programa de un juglar cazurro de hacia 1420. Pero esos fragmentos — junto con otros poemas - se hallan copiados en las últimas hojas de un códice cronístico, de gran tamaño, que nunca pudo ser el que manejó o poseyó un juglar de clase ínfima. Se trata, en efecto, de apuntes de un predicador; los fragmentos del Libro de Buen Amor — todos ellos de carácter didáctico- no habrían pasado, por tanto, por una etapa de transmisión oral, y, desde luego, habrían llegado allí en circunstancias muy distintas a las evocadas por Ramón Menéndez Pidal. $^{12}$

\footnotetext{
${ }^{11}$ A pesar de que Núñez emplee la palabra "letras", Joaquín González Cuenca clasifica estas poesías como invenciones: véase su libro inédito Ceremonial de galanes: primera rebusca de invenciones y letras de justadores que tuvo la gentileza de facilitarme.

12 Véanse Menéndez Pidal 1957, 233-239 y 388-392 y Deyermond 1974.
} 
Un caso auténtico, aunque atípico, de transmisión oral es el de un curioso manuscrito conservado en el Archivo Diocesano de Cuenca, con los Proverbios morales del rabí Sem Tob ibn Ardutiel (Santob de Carrión), obra de mediados del siglo xIV. Un comerciante converso, Ferrán Verde, de unos sesenta años de edad, fue acusado en 1492 ante la Inquisición de Sigüenza y encarcelado durante cuatro años; uno de los cargos que se le hicieron fue el de que solía leer libros sospechosos, como "una obra de rrabí Sonto" (López Grigera 1976, 222). ${ }^{13}$ Ferrán alegó en su defensa que se había aprendido de memoria muchas coplas de los Proverbios morales, porque "yo era persona que procuraba saber muchas obras y escripturas", lo que había hecho en este caso a causa de sus "buenos castigos y enxemplos" (223224). Para demostrarlo, al cabo de cuatro años de cárcel, pidió que se le "mandase dar escrivanías et paper para las escrivir todas las [coplas] que supiese et a la memoria le viniesen [...] Digo que yo juro a Dios Nuestro Señor [...] por doquiera que se rrecuentan que yo non dexo ninguna dellas de quantas a la memoria me han venido ni he podido saber, commo quiera que eran mas" (229). Y, en efecto, logró recordar nada menos que 219 estrofas, a veces coincidiendo exactamente con otros códices. Ya nos lo recordaba Luisa López Grigera que existió una costumbre de memorizar los Proverbios morales, y tal vez de trasmitirlos oralmente. De hecho el prólogo de uno de sus códices dice: "Sin dubda las dichas trobas son muy notable escritura, que todo ome lo deviera decorar 'ca esta fue la entencio del sabio rrabý que las fizo: porque escritura rrimada es mejor decorada que non la que va por testo llano" (229). No sabemos exactamente cuáles fueron los motivos que indujeron a Ferrán Verde a memorizar — ¿de un manuscrito?, ¿de oídas? — tantas estrofas de un poema compuesto hacía siglo y medio, pero es realmente impresionante la fuerza de su memoria, y lo cierto

\footnotetext{
${ }^{13}$ En todas las citas que hago regularizo los acentos y el empleo de i/j y u/v según las normas actuales.
} 
es que aunque no se las hubiera recitado a nadie, sí que se las recitaría él mismo para conservarlas vivas en su memoria.

No se sabe mucho de la forma oral de los cuentos folklóricos en la Edad Media, pero en las colecciones de exempla - Libro de los assayaminetos de las mugeres (o de los engaños), Calila e Dimna, Libro de los gatos, Libro de los enxemplos por a.b.c., etc. - se nos ofrecen abundantes pruebas de su empleo por autores cultos. Es muy conocida, asimismo, la función que ejercían como ingrediente de los sermones populares. Sobre este último aspecto, carecemos todavía, en lo referente a España, de un estudio comparable al espléndido de Owst (1961) sobre el sermón inglés; pero sabemos que Pedro Cátedra ha trabajado sobre el tema.

Es probable que durante el siglo XIV Juan Manuel haya conocido muchos cuentos de oídas, pero procedentes de textos escritos: pasaba las noches de insomnio escuchando a quienes los leían (Macpherson 1973). Ésa puede ser la razón por la que se ha podido observar en sus enxemplos - tan literarios, por otra parte- la estructura típica del cuento oral (England 1977). De modo parecido, su Libro de las tres razones (mal llamado Libro de las armas) está formado por cuentos pseudohistóricos que él había oído, añadiendo los de su propia creación y, en conjunto, encerrados en una estructura fuertemente literaria (Deyermond 1982). No deja de ser irónico que este autor, que tanto tomó de la cultural oral, se obsesionase por la conservación de un manuscrito auténtico de sus obras y que el manuscrito, como se sabe legado al Monasterio de Peñafiel, se perdiera pronto. Una combinación parecida de elementos folklóricos — tal vez de transmisión oral- y de técnicas literarias muy esmeradas se encuentra dos siglos más tarde en el Lazarillo de Tormes, a propósito de lo cual conviene recordar la ambición literaria del autor ficticio, tal y como se manifiesta en el prólogo. ${ }^{14}$

\footnotetext{
${ }^{14}$ Véanse los trabajos sobre el Lazarillo de Tormes de Jones 1968, Lázaro Carreter 1972 y Frenk 1983.
} 
Origen más discutido es el de las facecias, anécdotas y dichos - literarios e históricos- que tanto se extendieron durante el siglo XVI. Maxime Chevalier ha editado y estudiado este precioso material, inclinándose por una hipótesis de origen oral, discutida por Donald McGrady, ${ }^{15}$ con ejemplos que resultan convincentes en algunos casos, pero que sería extremado generalizar a todo el campo, conociendo - incluso por el testimonio de géneros similares hoy- con cuánta frecuencia se nutren del testimonio y la transmisión oral.

No cabe dentro de este panorama necesariamente breve y sintético una consideración extensa de la posible oralidad de la literatura sapiencial (por ejemplo: colecciones de sententiae y de refranes), ni de los discursos políticos y su representación en la literatura. Quisiera hacer referencia a algunos otros aspectos y géneros, empezando por el del relato autobiográfico.

Los archivos de la Inquisición contienen una multitud de relatos autobiográficos de los acusados, que así se defendían de las acusaciones de testigos hostiles. Testigos y acusados emplean la narración oral: no estaría mal hacer una cala en su estilo para buscar las pautas que así lo delatan, por ejemplo del estilo formulario. ${ }^{16}$ Un poco más arriba se traía a colación el caso de Ferrán Verde. De sobra sabemos que en el periodo medieval no se suelen tratar estos testimonios como hechos literarios, cosa que sería plenamente factible, sobre todo cuando comprobamos el valor de estos relatos en los testimonios del siglo siguiente. Cercanas a este género histórico-documental se me antojan las Memorias de Leonor López de Córdoba (hacia 1400), emocionante relato de las dos épocas más turbulentas de su vida, al parecer dictado a un notario. ${ }^{17}$ Huelga decir que el Lazarillo pretende inscribirse en esa tradición.

15 Sobre el cuento oral véanse los trabajos de Chevalier 1975, McGrady 1976-77, y Frenk 1982, 110-111, cuya hipótesis se acerca más a la propuesta por Chevalier.

${ }^{16}$ Dos estudios de tales relatos de acusadores y acusados son los de Gilman 1978 y Edwards 1984.

17 Sobre Leonor López de Córdoba véanse los trabajos de Reinaldo Ayerbe- 
Muy comentada es la costumbre que había de leer los libros de caballerías ante un público (Frenk 1982, 107-109), pero quizá no sea tan conocido como se merece el caso del morisco Román Ramírez, médico y lector profesional de libros de caballerías. También fue acusado ante la Inquisición de Cuenca, en 1595, cuando tenía — como Ferrán- unos sesenta años. En la cárcel murió cuatro años más tarde. Uno de los cargos fue que, por inspiración diabólica, era capaz de recitar larguísimos fragmentos de libros de caballerías, sosteniendo en sus manos o bien una hoja en blanco o bien un libro puesto al revés:

Algunos de los que allí estaban que le conocieron dixeron al dicho Román: "Ca díganos un pedaço de tal libro de caballerías" que allí le señalaron, y de tal capítulo dél, y el dicho Román sacó un papel en blanco de la faldriquera, e mirando a él como leyendo essa escriptura dixo un gran pedaço del libro y capítulo que le señalaron. (Harvey 1974, 280) ${ }^{18}$

Otro testigo señaló que lo hacía de memoria, y Ramírez confirma:

Antes que él supiese leer ni lo hubiese deprendido, sabía ya de memoria los más libros de caballerías de los cuales dichos porque Román Ramírez, padre deste confesante, leía muy bien y muchas veces en presencia deste, y así este confesante iba tomando en la memoria lo que le oía leer. (Harvey 1974, 282-296)

La defensa era convincente contra la acusación de brujería. Cuando se le somete a una prueba de memoria el acusado confiesa que:

Chaux, 1977-78, quien incluye una edición del texto, y Deyermond 1983, 29-37. Además, según me informa el profesor Ayerbe-Chaux, hay una tesis importante de Amanda Curry (1985).

${ }^{18}$ En una ponencia del Coloquio de Novi Sad. Liu Kuili dijo que "In Tibet, there... is also a folk singer who always takes a piece of paper (no matter what kind of paper it is) in his hand when he recites epic tales. According to him, he sees on the paper fighting scenes of the heroes" (cito de la traducción inglesa). 
tomaba en la memoria [...] la sustancia de las aventuras y los nombres de las ciudades, reinos, caballeros y princesas [...]; y después, cuando lo recitaba, alargaba y acortaba en las raçones cuanto quería. (Harvey 1974, 283-297)

O sea, como comenta L. P. Harvey, que improvisaba libros de caballerías del mismo modo que los cantores yugoeslavos improvisaban poemas épicos. Hasta parece que el bueno de Román Ramírez compuso su propia obra, Florisdoro de Grecia, y dictó una de sus partes a un amanuense $(1974,284-98) .{ }^{19}$

Me gustaría tratar de la oralidad en la Celestina: la sintaxis auténtica del habla popular, el empleo de registros distintos conforme al interlocutor, la importancia fundamental del diálogo y de la memoria, los giros coloquiales, la actitud de los personajes y de los autores frente a la retórica, la presentación oral de la obra según Fernando de Rojas y según Alonso de Proaza...; pero es tema de todo un libro y no de la última parte de un artículo panorámico. ${ }^{20}$

La oralidad influye en casi todos los géneros literarios que nos ofrece esta época de transición, sea de una o de otra manera. A veces se trata de un género tradicional —oral en sus orígenes y hasta en su esencia- que se transforma en literatura escrita, como los romances y los refranes. A veces un género culto se "oraliza", como la transmisión oral-memorial de los Proverbios morales de Sem Tob, o la composición oral de libros de caballerías. A veces un género culto aprovecha la oralidad hasta el punto de erigirse en documento históricolingüístico, como los sermones populares o aspectos de la Celestina.

19 Daniel Eisenberg dice de la composición de Florisdoro de Grecia por Román Ramírez: "there is considerable doubt about whether he ever did so" (1979, 70). En mi opinión, las conclusiones a las que llega Harvey sobre esta cuestión son convincentes.

${ }^{20}$ Existen varios estudios sobre dichos temas, veánse, por ejemplo: Severin 1970, Gilman 1974, cap. 2; Read 1983, cap. 4; Turano 1985; Gurza 1986; Seniff 1987, 164-65; Fraker 1990 y también es importante la bibliografía que cita al respecto Noguera 1988. 
De modo que la relación oralidad/cultura escrita en la época de transición entre Edad Media y Renacimiento se nos aparece como una transformación, como una superación, desde luego, pero también como una simbiosis.

\section{REFERENCIAS}

Armistead, Samuel G., 1963. A Lost Version of the "Cantar de gesta de las Mocedades de Rodrigo" Reflected in the Second Redaction of Rodríguez de Almela's "Compendio historial", Berkeley, University of California Press.

—, 1973. "Las Mocedades de Rodrigo según Lope García de Salazar", Romania 95, 303-320.

-, 1978. "The Mocedades de Rodrigo and Neo-Individualist Theory", Hispanic Review 46, 313-327.

Ayerbe-Chaux, Reinaldo, 1977-78. "Las memorias de doña Leonor López de Córdoba”, Journal of Hispanic Philology 2, 11-33.

Boase, Roger, 1978. The Troubadour Revival: A Study of Social Change and Traditionalism in Late Medieval Spain, London, Routledge and Kegan Paul [trad. esp. de Miguel Muro, El resurgimiento de los trovadores: un estudio del cambio social y el tradicionalismo en el final de la Edad Media en España, Madrid, Pegaso, 1981].

Chaytor, H, J., 1945. From Script to Print: An Introduction to Medieval Literature, Cambridge, Cambridge University Press.

Chevalier, Maxime, 1975. Cuentecillos tradicionales en la España del Siglo de Oro, Madrid, Gredos.

Clanchy, Michael T., 1979. From Memory to Written Record: England, 1066-1307, London, Edward Arnold; Cambridge, MA, Harvard University Press.

Curry, Kathleen Amanda, 1985. "Historia y literatura en las Memorias de doña Leonor López de Córdoba", tesis doctoral, Georgetown University.

Deyermond, Alan, 1974. “Juglar's Repertoire or Sermon Notebook? -The Libro de Buen Amor and a Manuscript Miscellany”, Bulletin of Hispanic Studies 51, 217-227. 
Deyermond, Alan, 1982. "Cuentos orales y estructura formal en el Libro de las tres razones (Libro de las armas)', en Don Juan Manuel: VII centenario, Murcia, Universidad-Academia Alfonso X el Sabio, pp. 75-87.

—, 1983. "Spain's First Women Writers", en Women in Hispanic Literature: Icons and Fallen Idols, Beth Miller (ed.), Berkeley, University of California Press, pp. 27-52.

—, 1989. "The Poetry of Nicolás Núñez", en The Age of the Catholic Monarchs (1474-1516, Literary Studies in Memory of Keith Whinnom, suplemento especial del Bulletin of Hispanic Studies, Liverpool, University Press, pp. 25-34.

Diez Borque, José María, 1985. "Conjuros, oraciones, ensalmos...: formas marginales de poesía oral en los siglos de oro", Bulletin Hispanique 87, 47-87.

EDWARDS, John, 1984. "Jewish Testimony to the Spanish Inquisition, Teruel, 1484-87", Revue des Études Juives 143, 333-350.

EISENBERG, Daniel, 1979. Castilian Romances of Chivalry in the Sixteenth Century. A Bibliography, Research Bibliographies and Checklists, 23, London, Grant \& Cutler.

England, John, 1977. “¿Et non el día del lodo?: The Structure of the Short Story in El Conde Lucanor", en Juan Manuel Studies, ed. Ian Macpherson, London, Tamesis, pp. 69-86.

Ferreira, Manuel Pedro, 1986. O som de Martin Codax: sobre a dimensão musical da lírica galego-portuguesa (séculos XII-XIV), Lisboa, Universidade e Imprensa Nacional-Casa da Moneda.

Fraker, Charles F., 1990. Celestina: Genre and Rhetoric, London, Tamesis.

FRENK, Margit, 1982. "'Lectores y oidores': la difusión oral de la literatura en el Siglo de Oro", en Actas del VII Congreso de la Asociación Internacional de Hispanistas I, Roma, Bulzoni, pp. 101-123.

—, 1983. "La ley del tres en el Lazarillo de Tormes", en Homenaje a José Manuel Blecua ofrecido por sus discípulos, colegas y amigos, Madrid, Gredos, pp. 193-202.

Gilman, Stephen, 1974. La Celestina: arte y estructura, trad. Margit Frenk Alatorre, Madrid, Taurus.

—, 1978. La España de Fernando de Rojas: panorama intelectual 
y social de 'La Celestina', trad. Pedro Rodríguez Santidrián, Madrid, Taurus.

Goldschmidt, E. Ph., 1943. Medieval Texts and Their First Appearance in Print, London, Oxford University Press for the Bibliographical Society.

González Cuenca, Joaquín (ed.), 1980. Cancionero de la Catedral de Segovia: textos poéticos castellanos, Ciudad Real, Museo de Ciudad Real.

Gurza, Esperanza, 1986. "La oralidad y La Celestina", en Renaissance and Golden Age Essays in Honor of D. W. McPheeters, Potomac, MD, Scripta Humanistica, pp. 94-105.

Harvey, L. P., 1974. "Oral Composition and the Performance of Novels of Chivalry in Spain", Forum for Modern Language Studies 10, 270-286.

Huizinga, Johan, 1924. The Waning of the Middle Ages: A Study of the Forms of Life, Thought and Art in France and the Netherlands in the Fourteenth and Fifteenth Centuries, trad. P. Hopman (reimpr. Harmondsworth, Penguin, 1955), trad. esp. de José Gaos, El otoño de la Edad Media: estudios sobre las formas de la vida y del espíritu durante los siglos XIV y XV en Francia y en los Países Bajos, Madrid, Revista de Occidente, 1929.

Jones, Cyril A., 1963. "Algunas versiones más del debate entre el cuerpo y el alma", Miscellanea di Studi Ispanici 6, 110-134.

—, 1968. "Lazarillo de Tormes: Survival or Precursor?", en Litterae hispanae et lusitanae: Festschrift zum fünfzigjährigen Bestehen des Ibero-Amerikanischen Forschungsinstitut der Universität Hamburg, Hans Flasche (ed.), München, Max Hueber Verlag, pp. 181-188.

LANG, Henry R. (ed.), 1902. Cancioneiro gallego-castelhano: The Extant Galician Poems of the Gallego-Castilian Lyric School (1350-1450), I, New York, Charles Scribner's Sons.

Lawrance, J. N. H., 1985. "The Spread of Lay Literacy in Late Medieval Castile", Bulletin of Hispanic Studies 62, 79-94.

LÁzaro Carreter, Fernando, 1972. "Lazarillo de Tormes" en la picaresca, Barcelona, Ariel.

López Grigera, Luisa, 1976. "Un nuevo códice de los Proverbios morales de Sem Tob", Boletín de la Real Academia Española 56, 221-281. 
LoRD, Albert B., 1960. The Singer of Tales, Cambridge, MA, Harvard University Press (Harvard Studies in Comparative Literature, 24).

—, 1974. "Perspectives on Recent Work on Oral Literature", Forum for Modern Language Studies 10, 187-210.

—, 1981. "Memory, Fixity, and Genre in Oral Traditional Poetries", en Oral Traditional Literature: A Festschrift Albert Bates Lord, Columbus, Ohio, Slavica Publishers, pp. 451-461.

—, 1986. "Perspectives on Recent Work on the Oral Traditional Formula", Oral Tradition 1, 467-503.

MacPherson, Ian, 1973. "Don Juan Manuel: The Literary Process", Studies in Philology 70, 1-18.

McGrady, Donald, 1976-77. "Notes on the Golden Age Cuentecillo (with Special Reference to Timoneda and Santa Cruz)", Journal of Hispanic Philology 1, 121-145.

Menendez Pidal, Ramón, 1910. L’Épopée castillane à travers la littérature espagnole, trad. Henri Mérimée, Paris, Armand Colin.

—, 1957. Poesía juglaresca y orígenes de las literaturas románicas: problemas de historia literaria y cultural, Madrid, Instituto de Estudios Políticos.

Noguera, Dolores, 1988. "La oralidad en el teatro: ensayo de una bibliografía actual", Edad de Oro 7, 209-222.

Norton, F. J. y Edward M. Wilson (eds.), 1969. Two Spanish Verse Chap-Books: "Romançe de Amadís” (c. 1515-19), "Juyzio hallado y trobado", London, Cambridge University Press.

Ochrymowycz, Orest R., 1975. Aspects of Oral Style in the Romances juglarescos of the Carolingian Cycle, University of Iowa Studies in Spanish Language and Literature, 17, Iowa, University Press.

Owst, G. R., 1961. Literature and Pulpit in Medieval England: A Neglected Chapter in the History of English Letters \& of the English People, Oxford, Basil Blackwell, $2^{\mathrm{a}}$ ed.

ReAD, Malcolm K., 1983. The Birth and Death of Language: Spanish Literature and Linguistics: 1300-1700, Potomac, MD, Studia Humanitatis.

RenorR, Alain, 1986. "Oral-Formulaic Rhetoric and the Interpretation of Written Texts", en Oral Tradition in Literature: Interpretation in Context, John Miles Foley (ed.), Columbia, University of Missouri Press, pp. 103-135. 
RodríGuez-MoñIno, Antonio, 1970. Diccionario bibliográfico de pliegos sueltos poéticos (siglo XVI), Madrid, Castalia.

—, 1973-74. Manual bibliográfico de cancioneros y romanceros impresos durante el siglo XVI, 2 tomos, Arthur L.-F. Askins (ed.), Madrid, Castalia.

Seniff, Dennis P., 1987. "Orality and Textuality in Medieval Castilian Prose", Oral Tradition 2, 150-171.

SeVerin, Dorothy Sherman, 1970. Memory in "La Celestina”, London, Tamesis.

Trapp, J. B. (ed.), 1983. Manuscripts in the Fifty Years after the Invention of Printing, London, Warburg Institute.

Turano, Leslie P., 1985. "Aristotle and the Art of Persuasion in $\mathrm{Ce}$ lestina", tesis doctoral inédita, Westfield College, University of London.

Vaquero, Mercedes, 1989. "The Tradition of the Cantar de Sancho II' in Fifteenth-Century Historiography: A Possible Influence of the Chanson de Roland", Hispanic Review 57, 137-154.

Whetnall, Jane, 1989. "Songs and Canciones in the Cancionero general of 1511", en The Age of the Catholic Monarchs 14741516: Literary Studies in Memory of Keith Whinnom, suplemento especial del Bulletin of Hispanic Studies, Alan Deyermond e Ian Macpherson (eds.), Liverpool, University Press, pp. 197207.

WhinNom, Keith 1968-69 [1970]. "Hacia una interpretación y apreciación de las canciones del Cancionero general de 1511", Filología 13, 361-381. 